\title{
UNITY AND DIVERSITY IN COMMUNICATION: INEVITABLE, PERMANENT CO-HABITATION, HARMONIOUS CO-EXISTENCE OR TWO FORCES WAITING TO CONVERGE?
}

\author{
Maria da Graça L. Castro Pinto \\ Universidade do Porto
}

\section{Introduction}

It is hard to approach the topic "unity and diversity in communication" without seeing in it a convergence of antagonic forces at least from two perspectives, not only because of the conjunction "and" but also because of the meaning of "communication".

It may therefore be read bearing in mind:

1. the phenomenon "globalization" and subsequently the effect of "the new powers in a global society"1, including, naturally, communication as power. One of the antagonic forces stems from the fact that although the aim of globalization is to create a homogeneous global society (see the dimension "unity") it is confronted with various local powers ${ }^{2}$. In order to obtain the expected "unity" in a harmonious way while preserving the positive aspects of diversity and therefore affording everyone equality of opportunities, among other things, it is

\begin{tabular}{|l|l|l|l|l|}
\hline Ilha do Desterro & Florianópolis & $n^{\circ} 44$ & p.189-209 & jan./jun. 2003 \\
\hline
\end{tabular}


necessary to rely on instruments of regulation which are expected to guarantee equality of benefits and interests in the different domains;

2. and the notion of "communication" - as a process and not as power in the above mentioned sense -, which has to do with sharing (cf. the notion of "unity") different points of view, different types of knowledge. In fact, communication would not exist if the difference among people was not taken into account and if there were no different contents to convey and share (Boulinier, 1989, p. 4). Finally, we could say that the essence of communication lies in the difference among the actors implied in it. Yet, the difference which is the essence of communication cannot exist without a common code, implying therefore "unity", which has to be mastered by the emissor(s) and receiver(s), as protagonists of the process of codification and decodification required by communication.

Modern societies have undergone very important changes in the last two decades and, among those changes, it is worthwhile noting the implications of the Internet and the World Wide Web in communication (De Klerk, 2002, p. 102 ).

Now, still in the realm of communication, the main challenge we are faced with in this century concerns the effort to eliminate the gap between the rich and the poor societies as far as possible giving the poor access to electronic communication also (Petra \& Gaurean, 2001, p. 3).

This challenge is intimately connected with the access to knowledge, in a kowledge-based society context and subsequently to globalization and modernization of the world, which should be served by the Internet in order to allow citizens the most efficient access to knowledge. In other words, efforts should be made to prevent any kind of technological divide (Petra \& Gaurean, 2001, p. 3), also leading to an undesirable knowledge divide, to prevent a situation in which there are citizens who "generate and utilize knowledge" and citizens who, on the other hand, "passively (...) [receive] knowledge from abroad and [are] deprived of the ability to modify it." (p.3) 


\section{How far may the Internet be considered a global medium?}

A question we may ask in this context is to what extent we can think of "the Internet and Web as enabling new forms of community or democratic empowerment" (Bolter, 2001, p. 205) leading to a desirable unity and even to a "cultural unity" based upon the improvement of "information exchanges", when the electronic technology is not available to everybody.

We may even add that there is not a significant number of people around the world who have access to the electronic wor(l)d (Snyder, 1998, pp. xxvi, and Moran \& Hawisher, 1998, pp. 81-82). Therefore, we may perhaps be led to think that it is not worthwhile discussing a problem which only concerns a very small percentage of our population (according to data from the 1990s only $2 \%$ of the world's population is connected to the Internet (Snyder, 1998, p. xxvi) ${ }^{3}$. We may even say, following Crystal (2001, p. 59), that the Internet is not after all the global medium it is thought to be.

In any case we must acknowledge that the "electronic revolution" has begun and that its effects [at different levels but also] at all levels of education are not to be ignored (Snyder, 1998, p. xxxiii).

It is however relevant to outline that in the developed countries Internet users are increasing in number and that, although virtual communities may to a certain extent be restricted, they are not restricted in the traditional sense. This means that popular culture and traditional high culture are both available at the same time, waiting in equality of circumstances for possible or potential users (cf. Bolter 2001, pp. 205 and 207). Thus, culture may be considered a unity mediated by diversity.

\section{The network culture}

If there is no longer an "ideal of high culture (...) as a unifying force" (Bolter, 2001, p. 205) and if we take into account the networking of culture, should we be concerned about cultural diversity? If we cannot 
speak of a single culture, can we, on the other hand, speak, in Bolter's words, of "special interest groups" (p. 206) or of a "network of interest groups" (p. 205)? The most suitable expression is perhaps "transnational network culture", a sort of culture which, by means of the new technologies of communication, may create a "dialogue" among countries regardless of their languages and cultures.

From the cultural point of view, we may say that we are now experiencing, in a sort of globalization process, the emergence of the erradication of differences between youth culture and parental culture (Smith \& Curtin 1998, p. 223, referring to Richard, 1996). In this respect, Smith and Curtin (1998) suggest that "by about 2010 the techno-cultural understanding and practices of the children described (...) will incorporate the whole sociocultural space called adulthood so that there is no computer technology 'alien' phenomenon as such." (p. 223). Really, the use of the Internet allows children [as well as adults] to createnew cultures (p. 224), i.e., "new ways to see the world", new experiences responsible for bringing a "new meaning to "cultural diversity"' (p. 224-225).

"Cultural plurality" may be another key-phrase in the sense that culture, as far as education is concerned, should be looked at in a broad, multicontextual way (Beavis, 1998, p. 242). Hence, I stress that "young people's experiences and needs (...) [as well as their] rapidly changing world" (Beavis, 1998, p. 242) should be considered in the school curricula. As far as the school curriculum is concerned, Crystal's view seems worthwhile outlining. He refers to the future inclusion of e-mail in the school curriculum because he sees it as a medium that it is not to be feared by virtue of its linguistic characteristics but instead as "an opportunity, not a threat, for language education." (p. 128).

The definition of culture - as has been said before - is constantly updated as culture is to be seen as "multiple and constantly subject to change" (Beavis, 1998, p. 238). High culture cannot therefore be taken as the main culture and we have to accept that, especially in terms of the new technologies, it co-exists with other kinds of culture, including popular culture. 
Yet, if we keep the emphasis on "high culture" - a view which regards "society and its future as significantly at odds with the rapid technological, economic and political change transforming late twentieth-century existence", and considers it a "minority culture significantly at odds with the experiences and textual pleasures of the bulk of society" (Beavis, 1998, p. 240) -, then we are not tolerant enough to conciliate past and present (cf. the notion of remediation (Bolter 2001, pp. 23 and ff.)) and the "work with computer and other electronic texts alongside those which have traditionally been our concern" (p. 245).

The best way for young people to penetrate high culture texts should be considered very seriously. A sensible proposal could perhaps be to approach it through young people's experience with popular culture ${ }^{4}$. Moreover, we must bear in mind that popular and mass media texts possess their own status and are "part of the lively, immediate and sophisticated reality of students' textual worlds (...)" (Beavis, 1998, p. 245). Indeed, we cannot decontextualise the younger generation in terms of culture. Hence, electronic forms of communication help us to reconsider the "cultural ideals inherited from printed genres and forms." (Bolter, 2001, p. 208). In the past, print technology may have led to a radical definition of culture ( $p$. 208); nowadays, it is important to be aware of the fact that "On the World Wide Web, as elsewhere, the distinction between high culture and popular culture has all but vanished" (p. 207) ${ }^{5}$. Yet, as Bolter adds, "the breakdown of the distinction between elite and popular literature (and art in general)" (p. 208) is one of the aspects of the redefinition of the above-mentioned cultural ideals. This also means that every form of cultural representation is now available to everybody through the new technologies and access is not difficult (Bolter, 2001, p. 207). To look at culture from this point of view is doubtless plural and offers everybody the possibility of embracing all kinds of cultural possibilities. In this respect, according to Bolter (2001, p. xi), "the [new] writing space offered by electronic technology" has to be seen as a "reforming and remediating 
potential [which] has probably not been exhausted." (p. 212). As far as text is concerned, however, Bolter calls our attention to the fact that "The future of text as a remediator of culture is uncertain, even if text (as hypertext) continues to serve a variety of functions in cyberspace." (p. 212).

If, in the realm of the "network culture", the notion of culture must be redefined, unity and diversity should also be understood from this perspective because it may happen that the hierachical distinctions the network culture tends to reject (Bolter, 2001, p. 208) may privilege the popular forms by means of the media (the Internet and the Web) which shape its mode of communicating ${ }^{6}$.

\section{The instruments of regulation in a harmonious global society}

If undesirable inequities are not supposed to exist either in communication or in other new powers of a harmonious global society, it is therefore crucial to take into account instruments of regulation, a "global government", for example, and not a system of "global governance without global government" (Grilo, 2002, p. 275, quoting Joseph Stiglitz), in order to prevent distortions within each country and among populations of different countries. This way of looking at the different aspects of globalization (economic, political, social, educational, health, environmental, human rights, etc.) tries to prevent undesirable inequities - only the undesirable diversities because there are diversities which should be preserved - and to promote "unity" as a common denominator which should be identified with quality and equality of opportunities. In this globalization process, it is consequently important to combine "a possible international planning", with "the means and the instruments created and experienced by the governments and the national powers" (Barreto, 2002, pp. 271-272). This is why Barreto (2002) thinks, although he is not entirely satisfied with this solution, that "intergovernmental and 
transgovernmental methods are the most suitable" (p. 272) in this context.

If, instead of the above-mentioned global aspects, we are faced with certain domains of communication of knowledge, scientific knowledge for example, we are not dealing with populations in the above sense but with restricted communities, "groups of specific interests" - with no pejorative meaning -, who are also supposed to be subject to instruments of regulation fitting for their domains. When we think of the scientific community, we may also think that their production is expected to be regulated, as well as their experiments. And we all know the role played nowadays by bioethics, for example. Indeed, we notice a continuous multiplication of regulating commissions designed to study the effects of the latest scientific developments and, as far as the scientific publications are concerned, we are also aware of the existence of the refereeing by peers who are asked to review the articles - and who we expect to be impartial - in order to guarantee quality and to restrict the possibility of error (Fiolhais, 2002, pp. 23-24). This would be a way to exercise regulation in a specific field in order to control the diversity of offers and methods used to reach the proposed aims and to attain unity in terms of quality.

As for communication, we have already outlined "diversity" regarding different societies/populations/experts as well as "unity" concerned with the electronic medium used to share knowledge (the Internet and the Web). In other words, in order to share knowledge through this new medium it is necessary both to be connected to the Net (an economic and technological problem) and to master the required language (an education problem because people must be in possession of a new literacy, "computency" according to Green (1996 apud Smith \& Curtin 1998, p. 229).

Due to its characteristics, the electronic environment has the advantage of providing the means to create a network of common interests of varied origins and to facilitate the access of users from all over the world to the most recent developments in the different domains. 
The offer of several kinds of information by the Internet as a medium may be seen as a meeting point of different interests for those who navigate looking for the last developments in their domains. Once again, diversity connected to the public interests meets a unity force represented by the medium used. This way of dealing with information/knowledge may also lead to discussions among peers in order to guarantee quality. In fact, it is undesirable to deal with the information available on the Internet without the necessary critical thinking (as for hypertext, see Landow, 1992, p. 160).

Nevertheless, although the Internet as a medium may be described as unifying, it does not mean that the language(s) used by those who navigate is/are incompatible with diversity/variety/ creativity. Crystal, (2001, pp. 241-242), for his part, emphasizes the creativity and diversity promoted by the Internet in terms of language. Therefore, he asserts that the Internet cannot be seen as the death of languages (cf. p. 241). On the contrary, the author manifests his appreciation of the new and informal forms of language which are used, and which reveal how the human linguistic faculty is alive and in good form (cf. p. 242).

The language the new technologies imply should not be confused with what Crystal (2001) calls "Netspeak" (pp. 17 and ff.) and which may take different forms according to the various Internet manifestations (language of e-mail, language of chatgroups, language of virtual worlds, language of the Web (Crystal, 2001, pp. 94-223). For example, as far as e-mail is concerned, Crystal writes: "At one level, it is extremely easy to define the linguistic identity of e-mail as a variety of language; at another level, it is surprisingly difficult" (2001, p. 94). And the author calls our attention to the fact that if "so many usage dictionaries, guides and rule books have appeared in recent years" (p. 62) it is certainly because the "linguistic identity of Netspeak, in its various Internet manifestations" (p. 62), is - according to Crystal - uncertain. 


\section{E-writing from a social point of view}

Let us however see in this "electronic language" a kind of informal language which may be the result of a social proximity between people which did not exist in the same degree before. In this context, e-mail correspondence, for instance, would allow proximity and improve not only "communicative-language use" but also "cross-cultural learning" (Knobel et al. 1998, p. 39) in a convergence effort - we may suggest - to balance diversity and unity.

When considering some of the texts available through the new ewriting facilities, Kress (1998, pp. 53-54) also underlines the changes in language, leading to a sort of informality connected to the social proximity that, on the one hand, the new technologies may instigate, and, on the other hand, the social context may favour. Thus, e-mail, as a "new medium" (cf. Moran \& Hawisher, 1998, p. 80), may be seen as producing new social relations (Kress, 1998, p. 54) ${ }^{7}$.

\section{Why shoud "Netspeak" be prefered to other terms?}

Crystal (2001, p. 17) prefers the term "Netspeak" to other terms, which may have different implications (see, for example, "Netlish", "Weblish", "Internet language", "cyberspeak", "electronic discourse", "electronic language", "interactive written discourse", "computermediated communication" (p. 17), because, according to his point of view, "Netspeak", as a term, "is succint, and functional enough, as long as we remember that 'speak' here involves writing as well as talking, and that any 'speak' suffix also has a receptive element, including 'listening and reading'." (pp. 17-18).

Moreover, Crystal adds that the interesting aspect of Netspeak has to do with the fact that it is a communication form which "relies on characteristics belonging to both sides of the speech/writing divide." (p.28). However, although Netspeak presents properties of speech and writing, it is similar to neither of them (Crystal, 2001, p. 47), it is more 
than a hybrid of speech and writing ${ }^{8}$, it may rather be considered a "third medium" or perhaps "a novel medium combining spoken, written, and electronic properties" (p. 48) . According to Crystal (2001, p. 47), Netspeak is closer to writing than to speech as far as its properties are concerned. Yet, it is not so easy to characterise it because of the existence of different Internet situations, from the Web to chatgroups ${ }^{10}$. Timing is also important in this context for, as Crystal writes, "Even apparently spontaneous Internet messages can involve elements of preplanning, pausing to think while writing, and mental checking before sending, which are simply not options in everyday conversation." (Crystal, 2001, p. 40). This quotation leads us to think of the properties of the Internet messages in terms of speech and writing and in terms of what it requires from the users from a (meta)linguistic point of view. Crystal (2001, p. 169) also underlines the linguistic interest of chatgroup language - a language he finds fascinating - because, in his opinion, "it provides (...) written language in its most primitive state" and "evidence of the remarkable linguistic versality that exists within ordinary people" (pp. 169-170).

Consequently Netspeak cannot be considered uniform; Netspeak may take different forms - and not only verbal - depending on the various situations and goals.

\section{The implications of multi-form Internet representations}

We are living a space, a cyberspace, with a specific new culture, where visualisation as a form of communication is becoming predominant (Bolter, 2001, chapter 4, entitled "The breakout of the visual"). According to Kress (1998, p. 55), "Visualisation is seen as an unproblematic kind of 'translation' from one semiotic mode into another - as a simplistic kind of translation from one language to another." Yet, as happens in all kinds of translations, some aspects inherent to the language point of departure may be lost and some others reinforced when we pass from one sort of language to another. If we are concerned 
with the quantity of conveyed information, due to its characteristics, the visual mode may be more efficient when larger amounts of information have to be processed. And the same may not happen when the displayed material is verbal (Kress, 1998, pp. 55-56).

The possibility exists, therefore, of combining different modes of representation and communication. It is worthwhile analysing this kind of combination carefully in terms of the users' learning and performing styles and in terms of a global communication based upon a type of communication (a predominantly visual one?) which, in spite of also being subject to cultural effects, may be seen as linguistically and culturally more neutral than, for instance, English as a global language (Kress, 1998, p. 57 $)^{11}$. It is worthwhile remarking that once again uncertainty is something which is peculiar to the domain of the new technologies. In the section "Language on the Web" of the 7th chapter of his book, Crystal (2001, pp. 216-218) shows how the presence of languages other than English has increased with the Internet's globalization. We can read (see p. 216) that, at a certain moment, the language of the Internet was English. Nevertheless, as the author writes, "The evidence is growing that this conclusion was wrong. The estimates for languages other than English have steadily risen since then [the growing of the Web], with some commentators predicting that before long the Web (and the Internet as a whole) will be predominantly nonEnglish, as communications infrastructure develops in Europe, Asia, Africa, and South America." (Crystal, 2001, p. 217-218). This quotation may lead us to think that natural language diversity is finally becoming an imposing force.

As has been outlined before, the new technologies experience constant changes. Therefore, it is very difficult to foresee what is going to happen even in the very near future and to predict the direction the hypertext/hypermedia developments will take. The electronic age seems to be subject to a variety of pressures and the multidisciplinary framework which it implies obliges us to be prudent in our predictions. 
Bolter (2001), for example, calls our attention to "the tension between the verbal and the visual representation [which he adds] seems more important than ever" (p. xii). In spite of the fact that he recognises that some of his prophetic claims did not come true when he published his book for the first time, he shares with us his predictions in this new edition, suggesting that he does not think that the computer will lead to a new kind of orality ${ }^{12}$. He rather predicts that communication will be visual (Bolter, 2001, p. xiii). At the end of the second edition of his book, entitled "Writing space", he even dares to change "visual communication" into "audiovisual communication" (p. 213) in the sense that Internet users will "seek to recapture the immediacy of phone and face-to-face conversation through real-time, video and audio conferencing over the Internet" (p. 213): a thought Bolter leaves in the form of a question. And the author finishes his book in a radical way: "It is fair to wonder whether the late age of print may also become the late age of prose itself." (p. 213).

Each user may then be faced with the challenge of creating and combining more and more sophisticated e-languages everyday depending on the demands.

\section{On the writings about the new technologies}

New demands are really a fact when the topic is concerned with Information and Communication Technologies (ICTs). In fact, it is almost an adventure to write about them, as there is always risk of being out of date. Therefore, any text may rapidly become obsolete by virtue of the changes continuously occurring in what Bolter (2001, p. xi) calls "the writing space offered by electronic technology"13. Interestingly, the same feeling is expressed by Crystal in his book "Language and the Internet". Crystal shares with us his concerns about the unpredictable effects of the permanent developments in the Internet revolution which may make the topics he dealt with in his book seem dated, although he only took nine months to write it (Crystal, 2001, p. ix). And he begins 
the last chapter of his book as follows: "It seems to be a standard convention for books dealing with digital technology to begin or end by warning their readers that everything they contain is going to be soon out of date" (p. 224). As his interest is especially in language, he also adds that there is no reason not to apply this convention to a linguistic perspective on the subject (p. 224).

And we should not forget, as Crystal underlines, that human beings show an impressive way of adapting themselves to new situations in terms of language too.

\section{The computer-based learning setting}

The implications of what has been pointed out are naturally very important when education becomes the topic of discussion. In this area, we cannot avoid mentioning the following aspects: "the relationships between individual learners and teachers; between teachers, learners and knowledge; and the internal cognitive and emotional states of the teacher and the learner" (Smith \& Curtin, 1998, pp. 227-228). It should not be forgotten either that children who are used to dealing with computers come to school with another attitude towards the world. They are used to searching for information, in a sort of anticipation of a "learning-by-doing model" (p. 226), predicting a "do-it-yourself home education" (p. 225). It is then no wonder that the familiarisation of these children with computer technology makes them prefer "participation, individual specialisation and access to information (...) to the imposition of learning" (p. 227) ${ }^{14}$. Following Landow (1992, p. 154), electronic hypertext/word requires an active learner/reader because as hypermedia users they have to be mentally active at the moment of dealing with information. Consequently, the traditional functions of teacher and student as well as the ones of reader and writer are questioned by this new technology (p. 153).

The famous "just-do-it" attitude of the younger generations towards computers and their familiarity with computer games make Smith and 
Curtin (1998, pp. 218-219) affirm, also based upon their study, that these practices obey those modes of learning which are directly controlled by the learner. It is worthwhile considering, for instance, the expression "kids just do it" in contrast with reading beforehand of the rules in the manuals (Smith \& Curtin, 1998, p. 219, referring to Turkle(1995), cited in McCorduck (1996, p. 162). This attitude is naturally distinct from the teaching approach which prepares the learner before practising by means of supplying the knowledge and skills which are supposed to be necessary (Smith \& Curtin, 1998, p. 219). We should perhaps look at this mode of learning controlled by the learner himself/herself as a way of keeping the learner motivated and try to generalise it to the learning setting in general.

If interactive technology enables the development of all senses, and consequently of different learning styles (by means of the forms of representation which it makes available), and in a certain way "guides" the learning process, avoiding external impositions, then we may consider this kind of approach close to the inductive one referred to by Felder (1993) and the most appropriate and advisable to instill motivation.

At this point, is it pertinent to suggest, if we take the learner as the starting point, that the use of the new technological environment provides a learning approach which conjugates unity and diversity in terms of the learning setting?

\section{The role of the teacher in the computer-based learning setting}

As far as the role of the teacher in the computer-based learning setting is concerned, Smith and Curtin (1998, p. 216) comment: "(...) research literature on the Internet suggests education benefits but advises teachers to guide students in their computer use so that motivation is maintained, and so that through 'searching' as opposed to 'surfing' students have a sense of direction and purpose." This quotation reminds us, as teachers or educators, of the need to create critical and independent minds, and to prepare the students to be able 
"to learn how to learn" and "to practise how to think" (Athans, 2001). The same concern is expressed by Landow who states that hypertextual environment helps to encourage critical thinking and reflective judgment (Landow, 1992, pp. 160 and 170).

Teachers naturally play an important role in this new learning setting and, when they are aware of the new challenges presented by it, they may be impelled to prepare individual programs in response to the needs of the population they have to work with (Smith \& Curtin, 1998, p. 227). In this new setting, teachers must also be prepared to assume a role of mediators, of facilitators (Lee, 2001), of more experienced "learners" rather than only the traditional role of lecturers because the didactic hypertext, following Landow, redefines the role of the teacher; in fact, part of his power and authority is transferred to the student (Landow,1992, p. 157) ${ }^{15}$. Once more, we are forced to be critical if we want to deal with diversity and unity in this context.

\section{Final remarks}

To conclude, I would like to stress how the new technologies may help us to interpret in a different way terms such as "multilingual" and "multicultural" and subsequently "unity" and "diversity". On the one hand, the new technologies can be expected to increase the global information space and, in this sense, to reduce the possible negative implications inherent to multilingualism as well as to multiculturalism, providing the best version of a global communication medium. On the other hand, the new communication technologies, due to their semiotic aspect and to their multicultural concerns, cover a diversity of "cultures" and "languages" offering an openness to literacies, to the new literacies, and consequently requiring a new type of training from those who wish to master them. It is even interesting to ask if it is not possible for there to be "transnational cultural networks" and at the same time a semiotic diversity of possibilities - a sort of "multilingualism" - crossing multilingual spaces where ICTs are concerned. 
The challenge at this moment also consists of looking at the future of a multicultural and multilingual world taking into account the advances of the ICTs as socially applied knowledge. Diversity of languages and cultures is naturally welcome; nevertheless we have to be aware of the facilities the new technologies, as a possible unity instrument, may provide and of the advantages they may present in order to guarantee equality of opportunities in terms of information and knowledge exchange when the topic is restricted to communication.

Regarding the new learning setting, it is important to think very seriously of the learners'way of dealing with it beginning by making the most of the learning facilities offered by the new technologies. It is perhaps worthwhile underlining once more the role of teachers as promoters of critical thinking, creativity and independent minds. Obviously, learners should always be critical towards the topics they are exposed to regardless of the medium used to convey them. But due to the diversity of the new technological offers, users are forced to be more critical than ever. Landow states that the electronic hypertext is a privileged medium to instigate critical thinking (Landow, 1992, p. 160).

Furthermore, the different forms of e-language should be seen as "an area of huge potential enrichment for individual languages" (Crystal, 2001, p. 241) and not as a threat. "The arrival of Netspeak is showing us homo loquens at its best" (Crystal, 2001, p. 242) seems to me the best possible way for Crystal to finish his book and the best quotation to show that, finally, human versatility, creativity and search for novelty have not been inhibited but rather instigated by the electronic technologies from a linguistic perspective.

In conclusion, it is my feeling that the interplay of the antagonic forces inherent to the terms "unity" and "diversity" connected to processes, such as communication, in which the protagonists are, on the one hand, the creativity of the homo loquens and, on the other hand, the unpredictable advances of the new information and communication technologies, will always have to take into account an "open space continuum". 


\section{Notes}

All the quotations from Portuguese sources were translated into English by the author and are of her entire responsibility.

1 See the title of the book Cidadania e novos poderes numa sociedade global. (Proceedings of the International Conference "Cidadania e novos poderes numa sociedade global" organised in 2001 by the Fundação Calouste Gulbenkian (Lisbon)), Lisboa, Fundação Calouste Gulbenkian e Publicações Dom Quixote, 2002.

2 See, for example, Petra and Gaurean 2001.

3 In the 1990s, the electronic technologies were restricted to a "gated community": only 2 percent of the world's population was connected to the Internet (see Snyder 1998, p. xxvi).

4 Beavis 1998, p. 241, asserts: "There are a number of arguments for including popular culture texts in the curriculum. One of the most persuasive is that of cultural inclusivity, coupled with the old pedagogical priority of 'starting from where the students are at'".

5 And Bolter 2001, p. 208, continues: "An unwillingness to distinguish between high art and popular entertainment has long been a feature of North-American culture, and we have chosen to confirm and accelerate this trend in the Web and other new media forms."

6 In Bolter's words, "netwok culture (...) finds in the Internet and the Web media that it can shape to express its preference for popular forms." (2001, p. 208).

7 According to Kress 1998, p. 54, e-mail produces new social relations because it creates an environment where the emissor and the receptor are put in co-presence resembling in a certain way the speech situation.

8 See Ierace 2001, p. 134.

9 As for Netspeak, Crystal 2001, p. 238, adds: "It is, in short, a fourth medium. In language studies, we are used to discussing issues in terms of 'speech vs. writing vs. signing'. From now on we must add a further dimension to comparative enquiry: 'spoken language vs. written language vs. sign language vs. computermediated language'." 
10 See Hilgert 2001, p. 53, as far as re-oralisation in Internet conversation is concerned.

11 More about the Internet "as a homogeneous linguistic medium" may be read in Crystal 2001, pp. 6 and ff.).

12 About the new orality experience in hypertextual fiction, and about the culture offered by computers which presents certain characteristics of an oral tradition culture, see Landow 1992, pp. 150-151 and p. 84 respectively. See also Hilgert 2001, p. 53, as far as re-oralisation in Internet conversation is concerned.

13 In this context, the terms "writing" as well as "reading" have become metaphorical expressions, cultural metaphors (see Bolter 2001, pp. 12 and 13).

14 The implications of this new computer-based learning setting are well illustrated as far as e-writing facilities are concerned by Bolter 2001, p. 115, when he writes: "These forms of digital dialogue make claims of immediacy or authenticity against the traditional essay. Unlike the traditional essay, they allow students to participate in an apparently immediate exchange of ideas and feelings that our culture associates with conversation."

15 For further comments on this topic, see Fiolhais 2002, pp. 150-154.

\section{Acknowledgments}

Special thanks go to my colleague João Veloso for his comments and for reviewing the references.

I am also grateful to my colleague Catherine Evangelista who helped me with the English.

\section{References}

Athans A. M. (2001). Portuguese research universities: Why not the best? Lecture presented at the Faculdade de Engenharia da Universidade do Porto, January 25th 2001.

Barreto, A. (2002). Sessão de Encerramento. Cidadania enovos poderes numa sociedade global, International meeting, Lisbon, 2001. In Cidadania e novos poderes numa sociedade global (pp. 267-272). Lisbon: Fundação Calouste Gulbenkian \& Dom Quixote. 
Beavis, C. (1998). Computer games, culture and curriculum. In I. Snyder (Ed.),. Page to Screen. Taking literacy into the electronic era (pp. 234-255). London/New York: Routledge, Taylor \& Francis. Reprinted 2001.

Bolter, J. D. (2001). Writing space. Computers, hypertext, and the remediation of print. (2nd ed.). Mahwah, New Jersey/London: Lawrence Erlbaum.

Boulinier, M. (1989). Le rythme et l'espace chez l'être humain. Lettre d'Information de l'Association Langage Lecture Orthographe, 7, oct., 3-4.

Crystal, D. (2001). Language and the Internet. Cambridge: Cambridge University Press.

De Klerk, F. (2002). Prioridades globais após o 11 de Setembro. In Cidadania e novos poderes numa sociedade global (pp. 101-112). Lisboa: Calouste Gulbenkian \& Dom Quixote.

Felder, R. M. (1993). Reaching the second tier: Learning and teaching styles in college science education. J. College Science Teaching, 23 (5), 286-290.

Fiolhais, C. (2002). A coisa mais preciosa que temos. Lisboa: Gradiva.

Green, B. (19981[996]). Literacy/technology/learning: notes and issues. Unpubl. discussion paper. Deakin Centre for Education and Change, Faculty of Education, Deakin University, Geelong, Victoria, cited by Smith, R.\& Curtin, P. In I. SNYDER (Ed.), Page to Screen. Taking literacy into the electronic era (p. 229). London/New York: Routledge, Taylor \& Francis. Reprinted 2001.

Grilo, E. M. (2002). Sessão de Encerramento. Cidadania enovos poderes numa sociedade global, International meeting, Lisbon, 2001. In Cidadania e novos poderes numa sociedade global (pp. 273-277). Lisbon: Calouste Gulbenkian \& Dom Quixote.

Hilgert, J. G. (2001). A construção do texto 'falado' por escrito: A conversação na Internet. In D. Preti (Ed.), Fala e escrita em questão (pp. 17-55). 2nd. ed. São Paulo: Humanitas FFLCH/USP,.

Ierace, G. (2001). Lo studente virtuale come autore on-line. Rivista di Psicolinguistica Applicata, I, 2, 121-147. 
Knobel, M., Lankshear, C., Honan, E. \& Crawford, J. (1998). The wired world of second-language education. In I, Snyder (Ed.), Page to Screen. Taking literacy into the electronic era (pp. 20-50). London/New York: Routledge, Taylor \& Francis. Reprinted 2001.

Kress, G. (1998). Visual and verbal modes of representation in electronically mediated communication: the potentials of new forms of text. In I. Snyder (Ed.), Page to Screen. Taking literacy into the electronic era (pp. 53-79). London/New York: Routledge, Taylor \& Francis. Reprinted 2001.

Landow, G. P. (1992). Hypertext. The convergence of contemporary critical theory and technology. Baltimore/London: The Johns Hopkins University Press. Version used: Hipertexto. La convergencia de la teoría crítica contemporánea y la tecnología. Barcelona: Paidós Ibérica, 1st. ed., 1995. Translated by Patrick Ducher.

Lee, V. (2001).An experiment with group learning in diversity. 2nd International Symposium of Students and Professors. University and its Students 2001. The contribution of the university to the unification of Europe in the new millenium. Charles University in Prague, Prague 12th-15th September 2001 (mimeo).

McCorduck, P. (1996). Sex, lies and avatars. Wired, April, 106-110, 158-165, referred to by Smith and Curtin 1998, p. 219.

Moran, C.; Hawisher, G. E. (1998). The rethorics and languages of electronic mail. In I. Snyder (Ed.), Page to Screen. Taking literacy into the electronic era (pp. 80-101). London/New York: Routledge, Taylor \& Francis. Reprinted 2001.

Petra, L.-A.; Gaurean, C.-B. (2001).University and our brave new knowledge-based society. 2nd International Symposium of Students and Professors. University and its Students 2001. The contribution of the university to the unification of Europe in the new millenium. Charles University in Prague, Prague 12th-15th September 2001 (mimeo).

Richard, B. (1996). Does culture industry take over? The sell-out of critical youth cultures in Germany. American Educational Research Association Annual Meeting 8-12 April, New York. Referred to by Smith \& Curtin 1998, p. 223.

Smith, R.; Curtin, P. (1998). Children, computers and life online: education in a cyberworld. In I. Snyder (Ed.), Page to Screen. Taking literacy into the electronic era (pp. 211-233). London/New York: Routledge, Taylor \& Francis. Reprinted 2001. 
Snyder, I. (1998). Page to screen. In I. Snyder (Ed.), Page to Screen. Taking literacy into the electronic era (pp. xx-xxxvi). London/New York: Routledge, Taylor \& Francis. Reprinted 2001.

Snyder, I (Ed.) (1998). Page to Screen. Taking literacy into the electronic era. London/ New York: Routledge, Taylor \& Francis. Reprinted 2001.

Turkle, S. (1995). Life on the screen: Identity in the age of the Internet. New York: Simon \& Schuster. Referred to by Smith \& Curtin 1998, p. 219. 